\title{
SOLAR FLARE PARTICLE EFFECTS AND SEASONAL RADIOCARBON VARIATIONS IN TREE RINGS OF THE NORTHERN AND SOUTHERN HEMISPHERES
}

\author{
PAOLO BARTOLOMEI, ${ }^{1}$ STEFANO CECCHINI, ${ }^{2}$ STEFANO CINI, ${ }^{1}$ MENOTTI GALLI ${ }^{3}$ \\ ROBERTO GAIMPIERI, ${ }^{1}$ CINZIA MONGARDI, ${ }^{4}$ TERESA NANNI ${ }^{5}$ and \\ AGOSTINO SALOMONI ${ }^{1}$
}

\begin{abstract}
Measurements of $\Delta^{14} \mathrm{C}$ and $\delta^{13} \mathrm{C}$, separately in early wood and late wood of two Mediterranean pine species, with a nearly year-long growth season, were made to better define possible solar flare particle effects. The measurements were made for suitable periods around the years of big flares (e.g., 1942, 1946, 1989) in Pinus pinea of the Adriatic area and Pinus halepensis from South Australia. We found that the ${ }^{14} \mathrm{C}$ concentration is consistently greater in early wood than in late wood of the same growth ring and considerably higher in the Australian samples than in the European samples. The data so far reveal no evidence of solar-flare effect.
\end{abstract}

\section{INTRODUCTION}

Time-dependent variations in the ${ }^{14} \mathrm{C}$ production rate are caused by changes in the galactic cosmicray flux as a consequence of solar modulation or by direct contribution from solar flares and nearby supernova explosions. As for solar-flare-induced variations, although high ${ }^{14} \mathrm{C}$ values are possibly attributable to flare events before the nuclear testing period, they are obscured, for recent solar cycles, by the large increase in atmospheric ${ }^{14} \mathrm{C}$ produced during the same period. At present, however, that contribution is greatly reduced, and the occurrence of large flare events comparable to that of February 23, 1956 (Shea 1990) encourages a search for their ${ }^{14} \mathrm{C}$ effects (cf. Lingenfelter and Ramaty 1970; Castagnoli and Lal 1980). The study of ${ }^{14} \mathrm{C}$ produced by solar flare particles, during periods when measurements of the energetic particle intensities and spectra, and observations of the Sun are available, plays a fundamental role in reconstructing past solar activity.

Following the investigations by Shea (1990) and Kostantinov et al. (1992), we present here a progress report on the search for ${ }^{14} \mathrm{C}$ abundance variations in tree rings induced by solar-flare particles. We made and repeated the measurements of possible local enhancement of ${ }^{14} \mathrm{C}$ production, both in the northern (NH) and southern hemispheres ( $\mathrm{SH})$, as an independent verification, because of the recent solar flares in September-October 1989, and checked for analogous effects from the large solar particle events of 1942 and 1946 (Pomerantz and Duggal 1974) (see Table 1).

\section{METHODS}

In the $\mathrm{NH}$, we used wood samples for a pine tree (Pinus pinea) of the Ravenna pine forest located ca. $3 \mathrm{~km}$ from the Adriatic Sea, Italy $\left(46^{\circ} \mathrm{N}\right)$; the samples were cut on 29 February 1992 . In the SH, we took samples from a pine tree (Pinus halepensis) located at the Belair National Park near Adelaide, Australia $\left(34^{\circ} \mathrm{S}\right)$; the samples were cut in September 1990 . Branches and trunks were dissected to obtain disks 2-4 cm thick. Each disk was then cut into four sections. The parts were sanded

\footnotetext{
${ }^{1}$ ENEA, Ente per le nuove Tecnologie, L'Energia e L'Ambiente, INN-FIS-DIAF, Via dei Colli 16, I-40136 Bologna, Italy ${ }^{2}$ Istituto di Technologie e Studio delle Radiazioni Extraterrestri del Consiglio Nazionale delle Ricerche, Via P. Gobetti 101, I-40129 Bologna, Italy

${ }^{3}$ Dipartimento di Fisica, Università degli Studi di Bologna, Via Irnerio 46, I-40126 Bologna, Italy

${ }^{4}$ Lavoro e Ambiente s.r.l., Via Musolesi 1, I-40138 Bologna, Italy

5Istituto per lo Studio dei Fenomeni Fisici e Chimici della Bassa ed Alta Atmosfera del Consiglio Nazionale delle Ricerche, Via P. Gobetti 101, I-40129 Bologna, Italy
} 
on both faces in order to see a well-defined ring structure. We started from the outermost ring using a 10-mm woodworking chisel. Where the separation of early wood from late wood faded, we made a preliminary incision with a cutter, which made the chisel positioning easier. Wood chips were cut into match-like pieces; the excess wood was then rubbed away until the next ring of the sequence was reached.

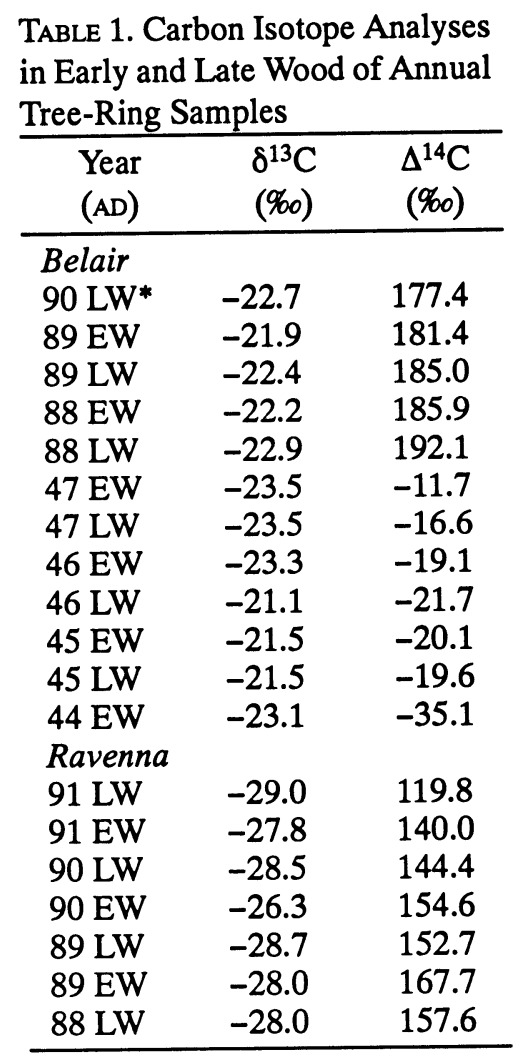

${ }^{*} \mathrm{LW}=$ late wood; $\mathrm{EW}=$ early wood

Chemical pretreatment consisted of boiling $50 \mathrm{~g}$ of wood in a $2 \mathrm{M}-\mathrm{KOH}$ solution for $8 \mathrm{~h}$. After a first waterflow washing, the sample was kept in a solution of $80 \mathrm{~g} \mathrm{NaClO}_{2}$ plus $110 \mathrm{ml}$ of $\mathrm{HCl}-1 \mathrm{M}$, in 3 liters of water, at $70-80^{\circ} \mathrm{C}$ for $24 \mathrm{~h}$. The sample was then drained, water washed, boiled in water for $3 \mathrm{~h}$ and rinsed until chlorides disappeared $\left(0.1 \mathrm{~N} \mathrm{AgNO}_{3}\right.$ test). The sample was then dried in an oven at $50-80^{\circ} \mathrm{C}$. This procedure isolates and purifies the cellulose fraction. $\mathrm{Ca} .15 \mathrm{~g}$ of cellulose for each sample were oxidized in a quartz oven and the benzene was synthesized via $\mathrm{Li}_{2} \mathrm{C}_{2}$ and $\mathrm{C}_{2} \mathrm{H}_{2}$. Average efficiency of the cellulose to benzene transformation was ca. 93\%. Teflon vials of $7 \mathrm{ml}$, filled with $4.395 \mathrm{~g}$ of benzene and $75 \mathrm{mg}$ of butyl-PBD, were used to determine ${ }^{14} \mathrm{C}$ activity.

To minimize any possible "memory effect" of the line, we performed various syntheses of benzene from the samples: modern standard (ANU sucrose) samples, cellulose samples, followed by the modern standard again. Before their use, each vial was identified for background and efficiency. Beta counting was done by a Wallac Quantulus $1220^{\mathrm{TM}}$; samples and standards were measured quasi-simultaneously for ca. 5 days for each vial. During counting, the standard quench parameter (external source) was continuously monitored; the endpoint spectrum variation was also monitored. It remained within three channels of the ${ }^{14} \mathrm{C}$ endpoint. These small endpoint variations were corrected every time by adjusting the counting window appropriately. 
Because we checked seasonal $\Delta^{14} \mathrm{C}$ variations, we considered separately the statistical and systematic components of the uncertainty. We evaluated the reproducibility of our measurements using four modern standards, which were oxidized during the sample analyses. The four activity values obtained for the modern standard, each having a 2\%o statistical uncertainty, show that the measurements became statistically self-consistent if uncertainty was multiplied by the factor 1.4. Because the statistical counting uncertainty for each sample was not $>2 \%$, the random error became $2.8 \%$. The systematic component of the uncertainty was $1.5 \%$, and the overall uncertainty was $3.2 \%$.

\section{RESULTS AND CONCLUSION}

Figure 1 shows $\Delta^{14} \mathrm{C}$ results for the Adelaide and Ravenna measurements in 1988-1991. For both sites, we made the measurements in early wood and late wood separately, as late wood-tracheids are supposedly produced in the late season (Attolini et al. 1990), i.e., after September-October-November in the Ravenna region. As can be seen in both graphs, the overall annual decreasing trend is consistent with the decrease of $10 \%$ per year observed in the atmosphere in various stations of the $\mathrm{NH}$, as reported by Levin et al. (1989). This is mainly due to nuclear test effects and to the Suess effect from fossil-fuel combustion.

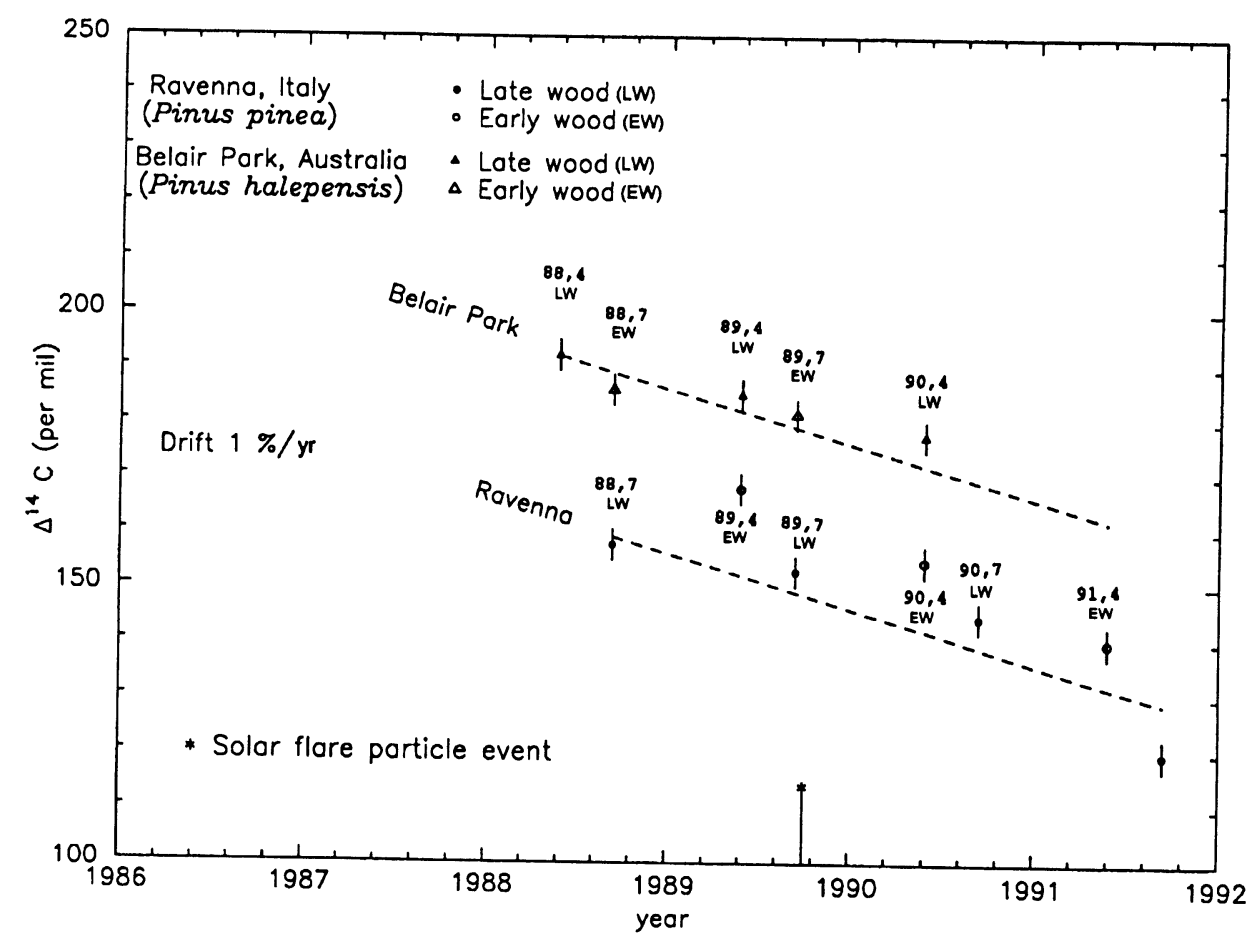

Fig. 1. $\Delta^{14} \mathrm{C}$ concentration in early and late wood of tree rings of the $\mathrm{SH}$ and $\mathrm{NH}$ for $1988-1991$. The quoted errors take into account statistical and systematic uncertainties. - - = decreasing trend of $1 \%$ per year. Also shown is the major solar flare particle event of September-October 1989.

The $\Delta^{14} \mathrm{C}$ values of the Australian samples, $c a .2 \%$ higher than the Ravenna samples, appear to be real, as the measurements were made simultaneously. On the contrary, Barbetti et al. (1992) for $\mathrm{AD}$ 1600-1800, Lerman, Mook and Vogel (1970) and Vogel, Fuls and Visser for AD 1835-1900 reported a $\Delta^{14} \mathrm{C}$ greater in the $\mathrm{NH}$ than in the SH. On the other hand, our $\Delta^{14} \mathrm{C}$ measurements (see Fig. 2) 
before the bomb-test period agree with the values found by Stuiver and Quay (1981) and Vogel, Fuls and Visser (1993). Suess-effect measurements in 1950 by the same authors seem to indicate a smaller fossil dilution in the SH (15\%) than in the $\mathrm{NH}(20 \%)$. However, it is difficult to attribute the difference we found only to this cause. The present time effect might be due to ${ }^{14} \mathrm{C}$ from nuclear explosions, occurring at different times in the SH and NH (see Tans, de Jong and Mook 1979; Olsson and Possnert 1992; Dai et al. 1992), and to its removal time constant, of ca. 25 yr (see Dai, Qian and Fan 1992). To verify this possibility, we plan to make more measurements using ancient dated wood, and compare them with the southern atmospheric ${ }^{14} \mathrm{C}$ concentration.

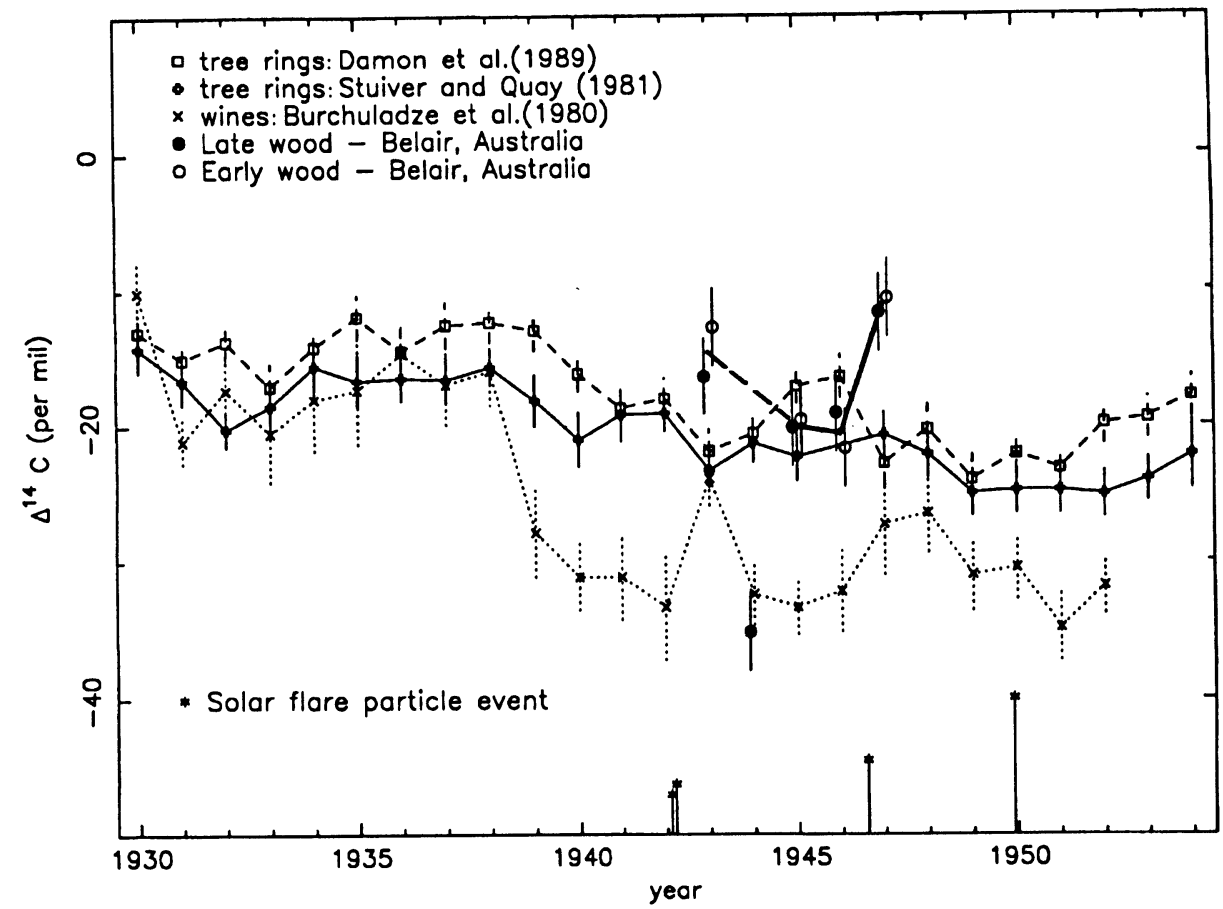

Fig. 2. Pre-bomb $\Delta^{14} \mathrm{C}$ concentration in early and late wood of tree rings of the SH. Measurements of Stuiver and Quay (1981) and Damon, Cheng and Linick (1989) in annual tree rings and of Burchuladze et al. (1980) in wines are shown for comparison. The segment height of major solar flare particle events is proportional to the total flux enhancement (Pomerantz and Duggal 1974).

For the Ravenna pine, the late-wood values of ${ }^{14} \mathrm{C}$ appear to be systematically lower than adjacent early wood. We also plan more investigations to verify if this effect could be caused by the area's proximity to a large, populated area, as suggested by the seasonal variation of $\mathrm{CO}_{2}$ concentration reported in Levin et al. (1989). Whether this effect is real or not, the coupling of early with late wood values provides an upper limit of the uncertainty of reproducibility.

In Figure 2, we also plotted the annual measurements of Stuiver and Quay (1981), Damon, Cheng and Linick (1989) and those from wines of Burchuladze et al. (1980). Our results seem a bit higher, but we cannot speak definitively of systematic differences. Although Figures 1 and 2 show significant variations between two subsequent measurements, none can be attributed conclusively to the solar-flare effect. However, for the solar flare years, 1942-1946, there seems to be an enhancement of the expected order of magnitude, according to Lingenfelter and Ramaty (1970). The time interval covered by our measurements is too small to allow an evaluation of solar modulation effects when 
comparing our results with sunspot index Rz or the magnetic index AA, as shown in Figure 3. We plan to continue the investigation, making more $\Delta^{14} \mathrm{C}$ measurements to find possible effects related to flares before 1950 . We also plan to clearly separate variations induced by solar activity and the Suess effect that may obscure the changes in ${ }^{14} \mathrm{C}$ production due to solar flares.

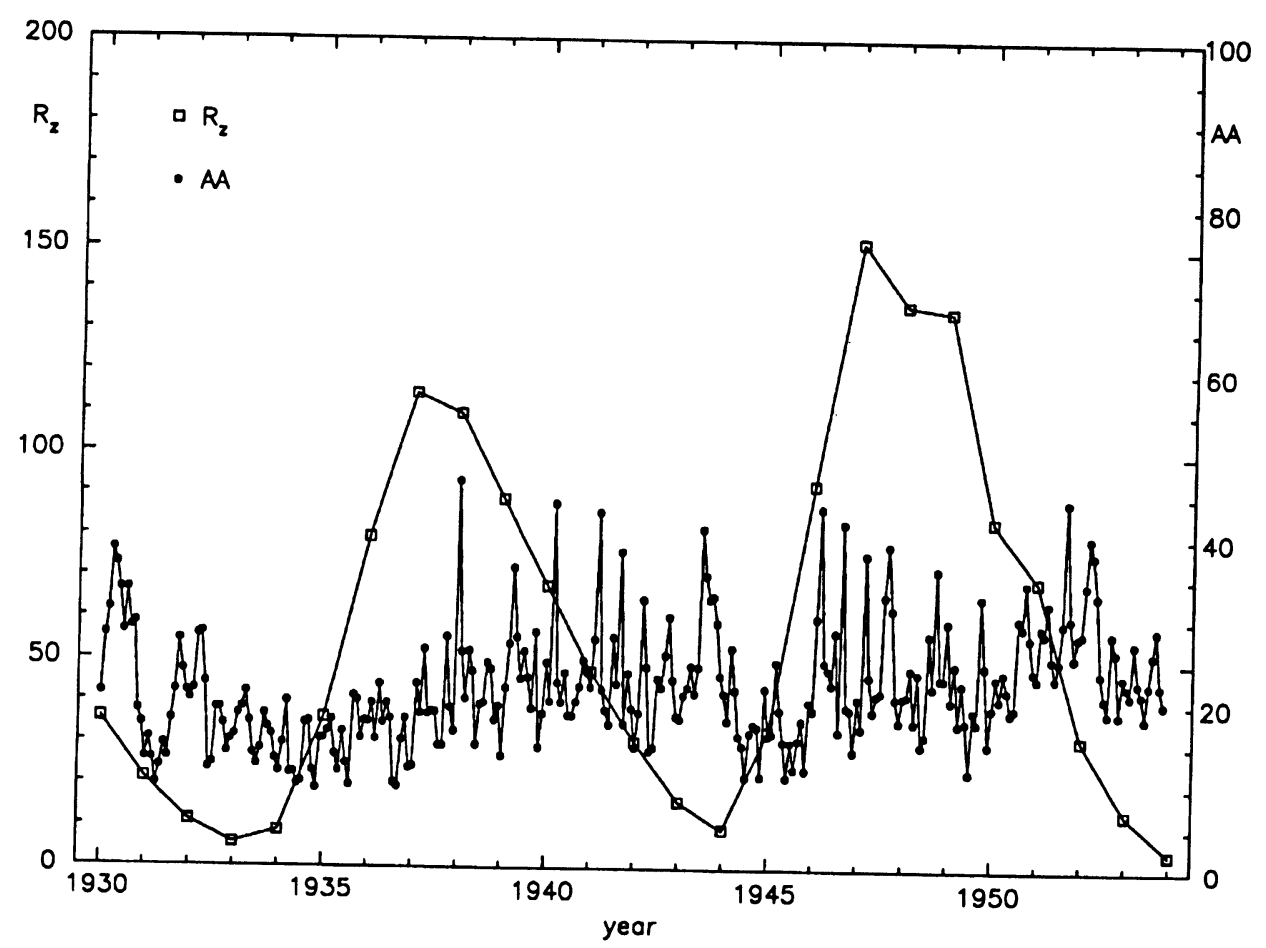

Fig. 3. Annual sunspot number $\left(R_{z}\right)$ and monthly AA index for the period AD 1930-1954 (Mayaud 1973)

\section{ACKNOWLEDGMENTS}

Thanks to the guidance and supervision of $\mathrm{H}$. Polach, the ENEA Radiocarbon Laboratory, Bologna, has recently improved its precision and reproducibility. We also thank the editors and P. E. Damon for giving us much advice on improving the text.

\section{REFERENCES}

Attolini, M. R., Calvani, F., Galli, M., Nanni, T., Ruggiero, L., Schaer, E. and Zuanni, F. 1990 The relationship between climatic variable and wood structure in Pinus Halepensis Mill. Theoretical Applications in Climatology 41: 121-127.

Barbetti, M., Bird, T., Dolezal, G., Taylor, G., Francey, R., Cook, E. and Peterson, M. 1992 Radiocarbon variations from Tasmanian conifers: First results from late Pleistocene and Holocene logs. In Long, A. and Kra, R. S., eds., Proceedings of the 14 th International ${ }^{14} \mathrm{C}$ Conference. Radiocarbon 34(3): 806-817.

Burchuladze, A. A., Pagava, S. V., Povinec, P., Toyon-

idze, G. I. and Usacev, S. 1980 Radiocarbon variation with the 11-year solar cycle during the last century. Nature 288: 320-322.

Castagnoli, G. and Lal, D. 1980 Solar modulation effects in terrestrial production of ${ }^{14} \mathrm{C}$. In Stuiver, M. and $\mathrm{Kra}$, R. S., eds., Proceedings of the 10 th International ${ }^{14} \mathrm{C}$ Conference. Radiocarbon 22(2): 133-158.

Dai, K.-M., Qian, Y. and Fan, C. Y. 1992 Bomb-produced ${ }^{14} \mathrm{C}$ in tree rings. In Long, A. and $\mathrm{Kra}, \mathrm{R}$. S., eds., Proceedings of the 14 th International ${ }^{14} \mathrm{C}$ Conference. $\mathrm{Ra}$ diocarbon 34(3): 753-756.

Damon, P. E., Cheng, S. and Linick, T. W. 1989 Fine and 
hyperfine structure in the spectrum of secular variations of atmospheric ${ }^{14} \mathrm{C}$. In Long, A., Kra, R. S. and Srdoc, D., eds., Proceedings of the 13th International ${ }^{14} \mathrm{C}$ Conference. Radiocarbon 31(3): 704-718.

Gupta, S. A. and Polach, H. A. 1985 Radiocarbon Dating Practices at ANU. Canberra, Australian National University.

Kostantinov, A. N., Levchenko, V. A., Kocharov, G. E., Mikheeva, I. B., Cecchini, S., Galli, M., Nanni, T., Povinec, P., Ruggiero, L. and Salomoni, A. 1992 Theoretical and experimental aspects of solar flares manifestation in radiocarbon abundance in tree rings. $R a$ diocarbon 34(2): 247-253.

Lerman, J. C., Mook, W. G. and Vogel, J. C. $1970{ }^{14} \mathrm{C}$ in tree rings from different localities. In Olsson, I. U., ed., Radiocarbon Variations and Absolute Chronology, Proceedings of the 12th Nobel Symposium. New York, John Wiley \& Sons: 257-299.

Levin, I., Schuchard, J., Kromer, B., and Münnich, K. O. 1989 The continental European Suess effect. In Long, A., Kra, R. S. and Srdo丈, D., eds., Proceedings of the 13th International ${ }^{14} \mathrm{C}$ Conference. Radiocarbon 31(3): 431-440.

Lingenfelter, R. E. and Ramaty, R. 1970 Astrophysical and geophysical variations ${ }^{14} \mathrm{C}$ production. In Olsson, I. U., ed., Radiocarbon Variations and Absolute Chronology, Proceedings of the 12th Nobel Sypmposium.
New York, John Wiley \& Sons: 513-535.

Mayaud, P. A. 1973 A Hundred Year Series of Geomagnetic Data 1868-1967: Indices aa, Sudden Storm Commencements. IAGA Bulletin 33. Paris, IUGG Publications Office: 121 p.

Olsson, I. U. and Possnert, G. $1992{ }^{14} \mathrm{C}$ activity in different sections and chemical fraction of oak tree rings, $A D$ 1938-1981. In Long, A. and Kra, R. S., eds., Proceedings of the 14 th International ${ }^{14} \mathrm{C}$ Conference. Radiocarbon 34(3): 757-767.

Pomerantz, M. A. and Duggal, S. P. 1974 Sun and cosmic rays. Review of Geophysics and Space Physics 12: 343-360.

Shea, M. A. 1990 Solar cosmic rays 1960-1989. In Proceedings of the 21st International Cosmic Ray Conference, Adelaide, Conference Papers 12: 196-201.

Stuiver, M. and Quay, P. D. 1981 Atmospheric ${ }^{14} \mathrm{C}$ changes from fossil fuel $\mathrm{CO}_{2}$ release and cosmic ray flux variability. Earth and Planetary Science Letters 53: 349-362.

Tans, P. P., de Jong, A. F. M. and Mook, W. G. 1979 Natural atmospheric ${ }^{14} \mathrm{C}$ variation and the Suess effect. Nature 280: 826-828.

Vogel, J. C., Fuls, A. and Visser, E. 1993 Pretoria calibration curve for short-lived samples, 1930-3350 BC. In Stuiver, M., Long, A. and Kra, R. S., eds., Calibration 1993. Radiocarbon 35(1): 73-85. 